\title{
Slope stability analysis with reference to rainfall infiltration in the Yongping Copper Mine, China
}

\author{
Yue Li*, Weiya Xu, Shengnian Wang*, Huanling Wang and Yongxin Dai
}

Due to the influence of rainfall infiltration, the slope of Yongping Copper Mine appears to have a high probability of instability, posing a great threat to the mineral transportation roads and mining safety. In this study, the hydraulic response of the slope under rainfall conditions is simulated, the response of the slope under different rainfall conditions is discussed, and the safety factor $\left(F_{S}\right)$ and the probability of failure $\left(P_{f}\right)$ of the slope during and after a rainfall are analysed. The results indicate that rainfall infiltration has a hysteretic effect on slope instability. The failure of the mining slope at the elevation between $178 \mathrm{~m}$ and $226 \mathrm{~m}$ is likely to occur in three days after a rainfall. The activity distribution of the slope indicates that it is an advancing landslide.

Keywords: Failure probability, open-pit mine, rainfall infiltration, safety factor, slope stability.

RAINFALL infiltration is recognized as a triggering factor in slope instability ${ }^{1-3}$. It can increase the weight of soil, resulting in an increase in effective sliding force. It can also decrease the matric suction $\psi$ of the soil, leading to reduction in shear strength of soil. The mechanical responses of a slope are therefore different in different zones at different times. A comprehensive study on the hydraulic response, failure mechanisms, and stability of a prospective slope is urgently needed ${ }^{4,5}$.

Traditionally, prediction of slope failures in response to rainfall infiltration relied mostly on recognition of terrain slope and identification of rainfall intensity $I$ and duration $D$ (refs 6,7 ). Caine ${ }^{8}$ proposed an empirical formula of limiting threshold of rainfall for slope instability: $I=14.82 D^{-0.39}$. Guzzetti ${ }^{9}$ extended Caine's research and proposed new global $I$ and $D$ thresholds by compiling 2626 rainfall events. However, the empirical method does not provide a theoretical framework for interpreting how rainfall infiltration affects slope stability. Many theoretical prediction models have been proposed since the $1990 \mathrm{~s}^{10-12}$. These models employed the effective stress principle in infinite-slope stability analysis; however, these results are always experiential because of the neglect of groundwater redistribution related to transient rainfall infiltration. Currently, numerical simulation is widely applied to make rainfall-induced slope failure analyses more accu-

\footnotetext{
Yue Li, Weiya $\mathrm{Xu}$ and Huanling Wang are in the Hohai University, Nanjing, 210098, China; Shengnian Wang is in the Nanjing Tech University, Nanjing, 210098, China and Yongxin Dai is in the State Key Laboratory of Safety and Health for Metal Mines, Sinosteel Maanshan Institute of Mining Research, Co, Ltd, Anhui, 243000, China.

*For correspondence. (e-mail: shengnian.wang@foxmail.com; yueh.1i@foxmail.com)
}

rate. For instance, $\mathrm{Chen}^{13}$ used a limit equilibrium method and numerical analysis to simulate the process of rainfall infiltration in a soil slope, and found that when the infiltrating rate exceeds one-tenth the value of the soil hydraulic conductivity, the pore-water pressure in a slope would not be dissipated in time. Raj and Sengupta ${ }^{14}$ simulated the rainfall-induced failures of a railway embankment at Malda, India, and pointed out that a significant reduction in $F_{S}$ would emerge when the values of $I$ and $D$ of a heavy rain are over $25 \mathrm{~mm} / \mathrm{h}$ and $12 \mathrm{~h}$ respectively. Lee ${ }^{15}$ used the Geo-Studio in providing an insight into the mechanism of a rainfall-induced landslide in the Hulu Kelang area and found that the redistribution of infiltrated rainwater in the soil mass was a reason for the slow response of failure mechanism to rainfall. All these methods greatly enriched the studies in rainfallinduced slope failure analysis. Moreover, many researchers believe that the randomness of soil properties in a slope and the uncertainty in values of $I$ and $D$ would affect the slope stability ${ }^{16-18}$. Therefore, a quantitative probabilistic slope analysis related to rainfall infiltration is necessary.

In this study, the Yongping Copper Mine slope was considered. The infiltration process in the slope was analysed by finite element method (FEM) during and after rainfalls. The changes in safety factor $F_{S}$ and the probability of failure $P_{f}$ of the slope were determined, and the failure mechanism of the rainfall-triggering slope was discussed.

\section{Overview of the Yongping Copper Mine}

\section{Geology of the study area ${ }^{19}$}

Yongping Copper Mine is located at the depression zone of Xinjiang fault in Jiangxi Province, China (Figure $1 a$ ). 

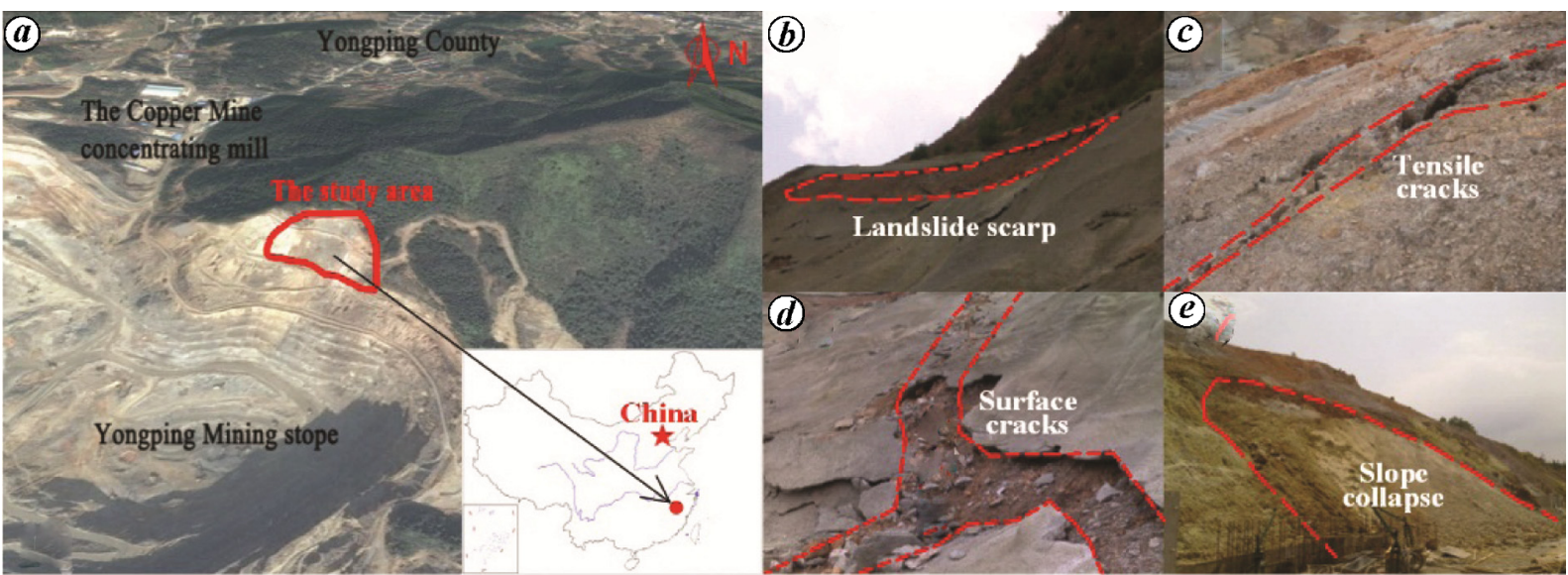

Figure 1. Site location and landslide signs.
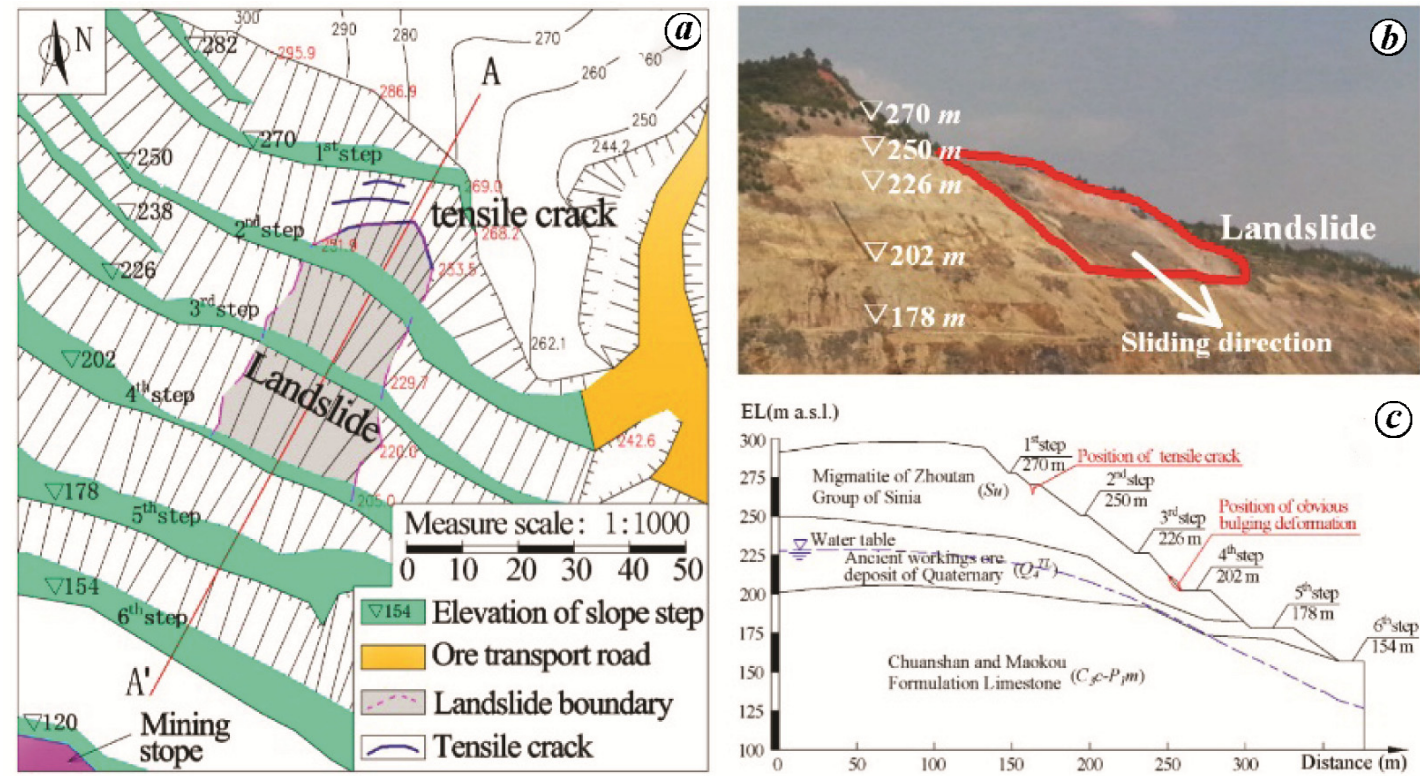

Figure 2. Topographic (a) and geomorphic (b) maps, and typical profile of the slope (c).

The geological location is E117 $45^{\prime} 36^{\prime \prime}-\mathrm{E} 117^{\circ} 46^{\prime} 12^{\prime \prime}$, $\mathrm{N} 28^{\circ} 12^{\prime} 00^{\prime \prime}-28^{\circ} 12^{\prime} 36^{\prime \prime}$. The main regional formations in the study area are migmatite $(\mathrm{Su})$ of Zhoutan Group of Sinian $\left(\mathrm{Z}_{1} \mathrm{zh}\right)$, Yejiawan Formation of mid-Carboniferous $\left(\mathrm{C}_{2} \mathrm{y}\right)$, Chuanshan Formation of upper Carboniferous $\left(\mathrm{C}_{3} \mathrm{c}\right)$, Maokou Formation of Lower Permian $\left(\mathrm{P}_{1} \mathrm{~m}\right)$, Lijia Formation of upper member of Lower Permian $\left(\mathrm{P}_{1} 1\right)$, and Holocene Series of Quaternary $\left(\mathrm{Q}_{4}\right)$. The main formation occurs nearly along the EW direction. The ground surface slope is $26-38^{\circ}$ above the elevation of $202 \mathrm{~m}$ amsl and $36-47^{\circ}$ below this elevation. Due to the past rainfall events, early signs of a new landslide, including surface cracks, bulging deformation and minor scraps (Figure $1 b-e)$, are observed. The distribution area of the landslide is about $5875 \mathrm{sq}$. $\mathrm{m}$ with thickness ranging from 10 to $25 \mathrm{~m}$. The total volume of the landslide is over $1 \times 10^{5} \mathrm{~m}^{3}$.

\section{Engineering geology and hydrological conditions}

The crown of the main landslide scarp appears in the shape of a round-backed armchair on a plane (Figure $2 a-$ $b)$. The slope includes three layers in its geological profile: migmatite of Zhoutan Group of Sinian ( $\mathrm{Su}$ ), ancient workings ore deposit of Quaternary $\left(\mathrm{Q}_{4}^{\mathrm{TL}}\right)$, and Chuanshan-Maokou Limestone Formation of Upper Carboniferous and Lower Permian $\left(\mathrm{C}_{3} \mathrm{c}-\mathrm{P}_{1} \mathrm{~m}\right)$ (Figure $2 c$ ). The $\mathrm{Su}$ layer is strong weathered rock mass with developed fractures $(\mathrm{RQD}=0)$ widely distributed in the middle and top of the slope. Rock quality designation (RQD) is an index used to evaluate the rock quality and is calculated by (SUM (length of core pieces $>100 \mathrm{~mm}$ )/total core run length) $\times 100$. The thickness of $\mathrm{Su}$ is approximately $1.7-$ $37.2 \mathrm{~m}$. The structure of $\mathrm{Su}$ is loose and prone to break up when it suffers from rainfall infiltration. The 
GENERAL ARTICLES

\begin{tabular}{|c|c|c|c|c|c|c|c|}
\hline Stratum & Items & $\begin{array}{c}\text { Water } \\
\text { content }(\%)\end{array}$ & $\begin{array}{l}\text { Gravity density } \\
\qquad\left(\mathrm{kN} / \mathrm{m}^{3}\right)\end{array}$ & $\begin{array}{c}\text { Compression } \\
\text { coefficient }\left(\mathrm{MPa}^{-1}\right)\end{array}$ & $\begin{array}{l}\text { Compression } \\
\text { modulus }(\mathrm{MPa})\end{array}$ & $C(\mathrm{kPa})$ & $\Phi\left(^{\circ}\right)$ \\
\hline \multirow[t]{5}{*}{ Migmatite (SU) } & Number of samples & 22 & 19 & 13 & 13 & 8 & 8 \\
\hline & Maximum value & 26.80 & 23.10 & 0.38 & 25.72 & 102.00 & 37.40 \\
\hline & Minimum value & 15.80 & 19.20 & 0.06 & 4.53 & 17.00 & 14.80 \\
\hline & Standard deviation & - & / & - & - & 8.03 & 2.11 \\
\hline & Average value & 22.83 & 20.43 & 0.21 & 9.30 & 73.60 & 25.05 \\
\hline \multirow[t]{5}{*}{ Deposit $\left(\mathrm{Q}_{4}^{\mathrm{TL}}\right)$} & Number of samples & 17 & 14 & 13 & 13 & 17 & 17 \\
\hline & Maximum value & 25.40 & 23.10 & 0.46 & 18.82 & 131.00 & 34.80 \\
\hline & Minimum value & 17.40 & 18.10 & 0.09 & 3.97 & 20.40 & 1.90 \\
\hline & Standard deviation & - & - & - & - & 9.45 & 3.24 \\
\hline & Average value & 22.20 & 20.30 & 0.21 & 10.08 & 69.23 & 23.57 \\
\hline
\end{tabular}

Table 2. Rock properties of the stratum

\begin{tabular}{|c|c|c|c|c|c|c|c|c|}
\hline \multirow[b]{2}{*}{ Stratum } & \multirow[b]{2}{*}{ Items } & \multirow{2}{*}{$\begin{array}{l}\text { Gravity } \\
\text { density } \\
\left(\mathrm{kN} / \mathrm{m}^{3}\right)\end{array}$} & \multirow{2}{*}{$\begin{array}{c}\text { Elastic } \\
\text { modulus } \\
(\mathrm{GPa})\end{array}$} & \multirow{2}{*}{$\begin{array}{l}\text { Poisson's } \\
\text { ratio }\end{array}$} & \multicolumn{2}{|c|}{$\begin{array}{l}\text { Uniaxial compressive } \\
\text { strength }(\mathrm{MPa})\end{array}$} & \multirow[b]{2}{*}{$C(\mathrm{MPa})$} & \multirow[b]{2}{*}{$\Phi\left(^{\circ}\right)$} \\
\hline & & & & & Dry & Saturated & & \\
\hline \multirow[t]{3}{*}{ Limestone $\left(\mathrm{C}_{3} \mathrm{c}-\mathrm{P}_{1} \mathrm{~m}\right)$} & Number of samples & 9 & 9 & 9 & 18 & 18 & 8 & 8 \\
\hline & Maximum value & 28.00 & 154.75 & 0.16 & 110.50 & 120.20 & 12.90 & 28.37 \\
\hline & Minimum value & 26.60 & 62.01 & 0.05 & 27.60 & 25.50 & 10.30 & 24.70 \\
\hline
\end{tabular}

$\mathrm{Q}_{4}^{\mathrm{TL}}$ layer formed from ancient mining activities is a complex mixture of fine clays, migmatite-limestone fragments, hillock, waste residue, safety pillar and rotten wood. The maximum thickness of $\mathrm{Q}_{4}^{\mathrm{TL}}$ is about $73.3 \mathrm{~m}$. The lithology of $\mathrm{C}_{3} \mathrm{c}-\mathrm{P}_{1} \mathrm{~m}$ is good $(\mathrm{RQD}=65-72)$. $\mathrm{C}_{3} \mathrm{c}-\mathrm{P}_{1} \mathrm{~m}$ occurs $\mathrm{N} 55^{\circ}-150^{\circ} \mathrm{E}, \mathrm{SW} \angle 30^{\circ}-55^{\circ}$.

The region is subjected to the influence of subtropical oceanic monsoons with abundant precipitation. According to 25 -year rainfall records ${ }^{19}$, the maximum annual precipitation is $2868 \mathrm{~mm}$, and the maximum daily precipitation is $238 \mathrm{~mm}$. Most of the precipitations take place between April and July, yielding nearly half of the total annual precipitation. In 110 annual rainfall events, there are more than $80 \%$ of the events having a rainfall intensity $50 \leq I<100 \mathrm{~mm} / \mathrm{d}$. Therefore, $I=75 \mathrm{~mm} / \mathrm{d}$ is used as the most frequent rainfall.

Hydrogeological condition in this area is relatively simple; the precipitation is the only source of groundwater supplement. According to the results of in situ water injection test and water pressure test ${ }^{19}$, both the $\mathrm{Su}$ and $\mathrm{Q}_{4}^{\mathrm{TL}}$ have a high permeability; therefore, water spreads downward rapidly when rainwater flows into the slope.

\section{Evolution tendency of slope failure}

Geological studies indicate that the landslide body has a weak shear strength and a high permeability. When the landslide body is subjected to rainfall infiltration, the shear strength reduces significantly. Due to the latest per- sistent rainfall, three new sub-landslides are observed. Two of them are small-scale landslides, the sliding surfaces of which do not pass through the second step. The other exhibits tensile crack (the occurrence is $\mathrm{N} 40^{\circ} \mathrm{W}$, $\mathrm{SW} \angle 80^{\circ}$ ) at the first step. The landslide crown has a width of $0.4 \mathrm{~m}$ with a depth of $0.8 \mathrm{~m}$. The elevation difference of the main scarp is about $3.7 \mathrm{~m}$. The toe of the sliding surface is exposed at the fifth step, with a width of $26.4 \mathrm{~m}$, and exhibits obvious bulging deformation. The sliding direction of the landslide is $\mathrm{S} 10^{\circ} \mathrm{W}$. As a whole, the stability of the landslide is low.

\section{Methodology and parameter determination}

The safety factor $F_{S}$ is calculated to analyse the stability of the slope under rainfall infiltration. The physical and mechanical parameters of soil and rock masses are listed in Tables 1 and 2. In order to simplify the computation process, the average value of each parameter is used. The $F_{S}$ is defined as

$$
F_{S}=\sum \tau_{r} / \sum \tau_{m}
$$

where $\tau_{r}$ is the resistant shear force and $\tau_{m}$ is the mobilized shear force. The matric suction $\psi$, which can be derived from unsaturated seepage analysis is given by $\psi=\psi_{a}-\psi_{w}$, where $\psi_{a}$ is the pore air pressure and $\psi_{w}$ is the pore water pressure. According to the Mohr-Coulomb failure criteria for unsaturated soil ${ }^{20}$, the shear strength of 


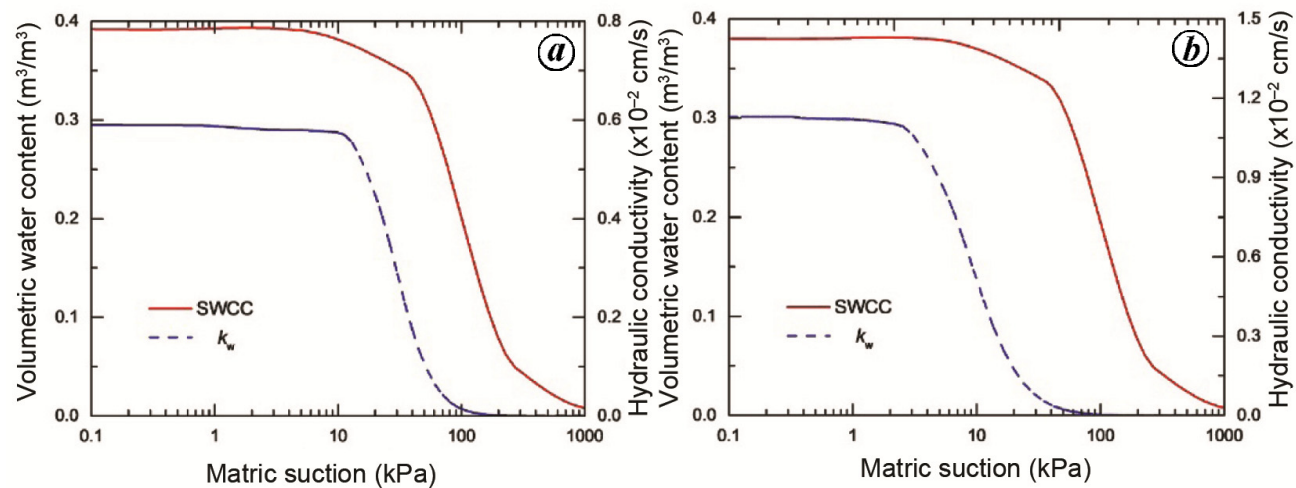

Figure 3. SWCC and $k_{w}$ curve of (a) SU and (b) $\mathrm{Q}_{4}^{\mathrm{TL}}$.

(a)

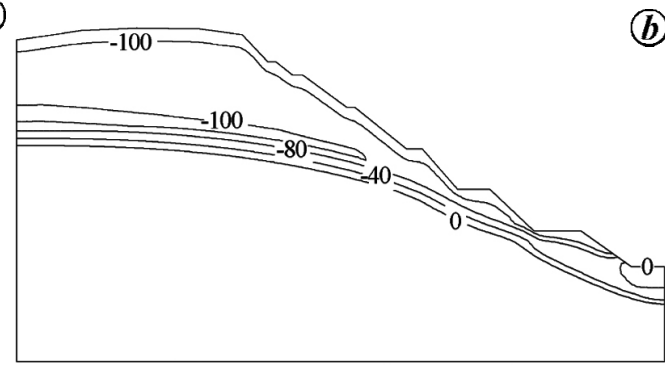

(b)

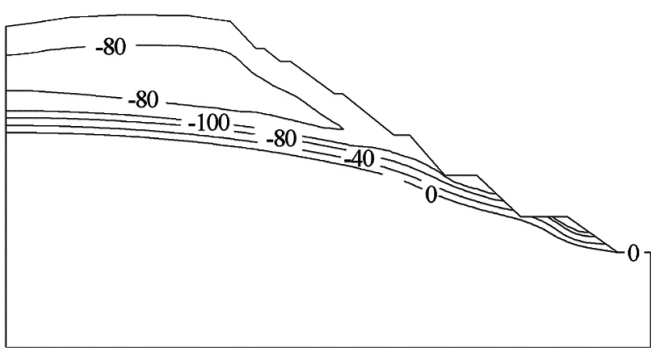

(c)

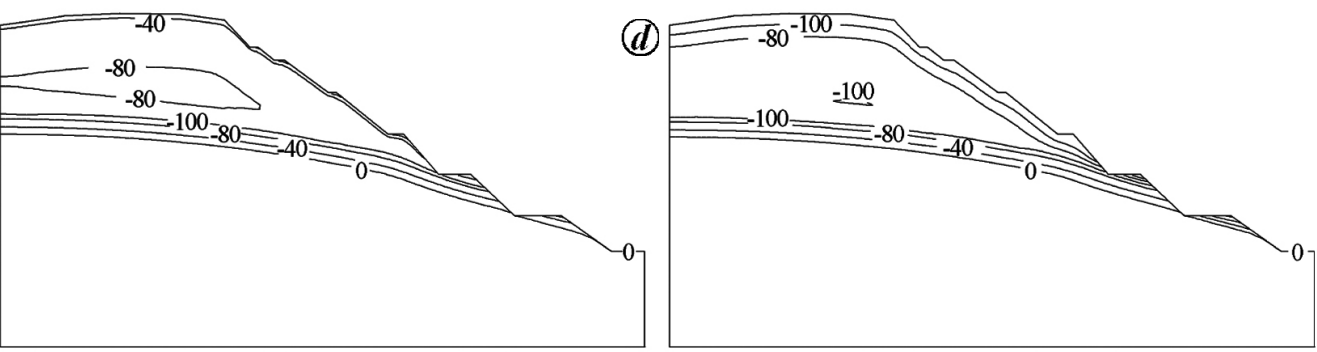

Figure 4. Distributions of $\psi_{w}$ under different rainfall conditions, $\boldsymbol{a}, 1$-day rainfall; $\boldsymbol{b}, 3$-day rainfall; $\boldsymbol{c}, 3$ days after rainfall; $\boldsymbol{d}, 7$ days after rainfall.

an unsaturated soil employing the effective stress principle can be expressed as ${ }^{21}$

$$
\tau_{r}=c^{\prime}+\left(\sigma-\psi_{a}\right) \tan \varphi^{\prime}+\left(\psi_{a}-\psi_{w}\right) \tan \varphi^{b},
$$

where $c^{\prime}$ is the effective cohesion, $\sigma$ the total stress, $\varphi^{\prime}$ the effective internal friction angle, and $\varphi^{b}$ is the angle of resistance with respect to $\psi$.

In the unsaturated seepage analysis, Richard's equation $^{22}$ is most widely used for describing water movement in the soil. The hydraulic conductivity $k_{w}$ is a variable related to the volumetric water content $\theta_{w}$. If the fluid is considered to be incompressible, the water flow through the unsaturated soil can be expressed as

$$
\frac{\partial}{\partial x}\left[k_{w x}\left(\theta_{w}\right) \frac{\partial H}{\partial x}\right]+\frac{\partial}{\partial y}\left[k_{w y}\left(\theta_{w}\right) \frac{\partial H}{\partial y}\right]+Q=\frac{\partial \theta_{w}}{\partial t},
$$

where $H$ is the total water head, $Q$ the applied boundary flux, $t$ the time, and $k_{w x}\left(\theta_{w}\right)$ and $k_{w y}\left(\theta_{w}\right)$ are functions of $k_{w}$ in $x$ and $y$ directions, which may vary with variations of soil properties or matric suction $\psi$. van Genuchten ${ }^{23}$ proposed a closed form equation to describe $k_{w}$ as follows

$k_{w}\left(\theta_{w}\right)=k_{S}\left[1-\left(a \psi^{(n-1)}\right)\left(1+\left(a \psi^{n}\right)^{-m}\right)\right]^{2} /\left[1+(a \psi)^{n}\right]^{m / 2}$,

where $\theta_{w}=\theta_{r}+\left(\theta_{S}-\theta_{r}\right) /\left[1+(\psi / a)^{n}\right]^{m}, \quad k_{S}$ is saturated hydraulic conductivity, $\psi$ can be derived from the soilwater characteristic curve (SWCC), $a$ the air-entry value of the soil, approximately equal to $(\sqrt[m]{2}-1)^{1-m} / \psi, m$ is a parameter that is related to the residual water content, and $n=1 /(1-m)$. The parameters for the fitting of SWCC and $k_{w}$ function are shown in Table 3 . The corresponding curves are presented in Figure 3, in which the phreatic surface is initialized according to the in situ drilling data ${ }^{19}$.

Due to the randomness and uncertainty of soil properties, Rosenblueth method is applied to estimate the change of $P_{f}$ during rainfall infiltration. $P_{f}$ is given by

$$
P_{f}=1-\Phi(\beta),
$$

where $\beta=\mu_{Z} / \sigma_{Z}, \mu_{Z}$ the average value of the parameter and $\sigma_{Z}$ is the standard deviation of the parameter. 

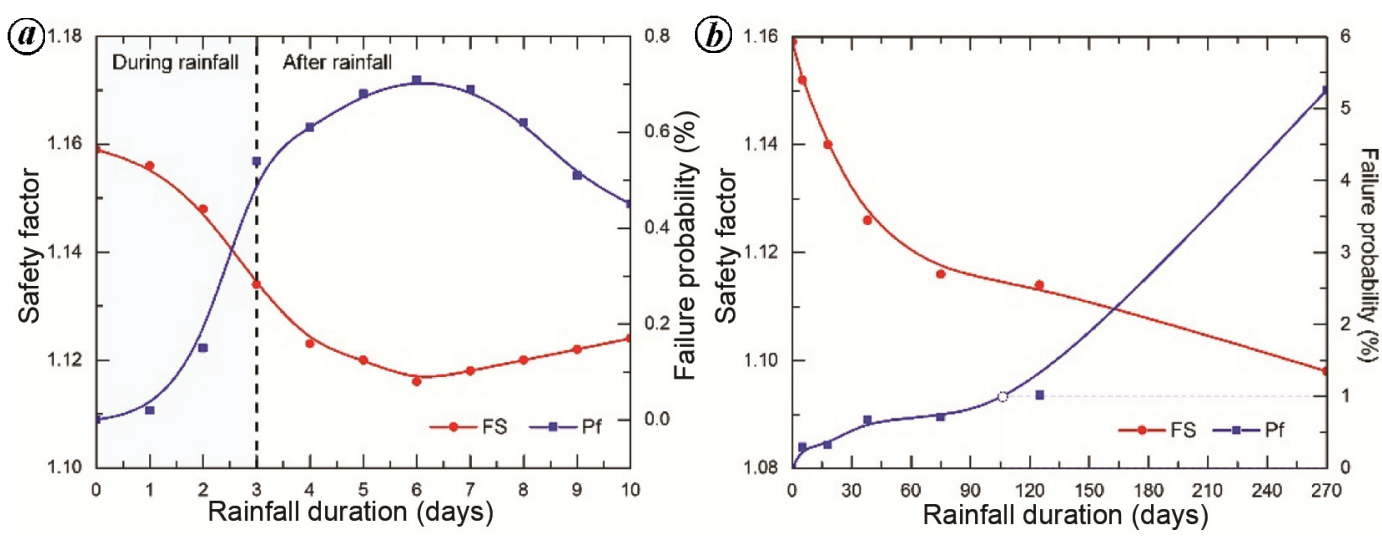

Figure 5. $\quad F_{S}$ and $P_{f}$ of the slope under different (a) 1-day rainfall; (b) 3-day rainfall; (c) 3 days after rainfall; (d) 7 days after rainfall.
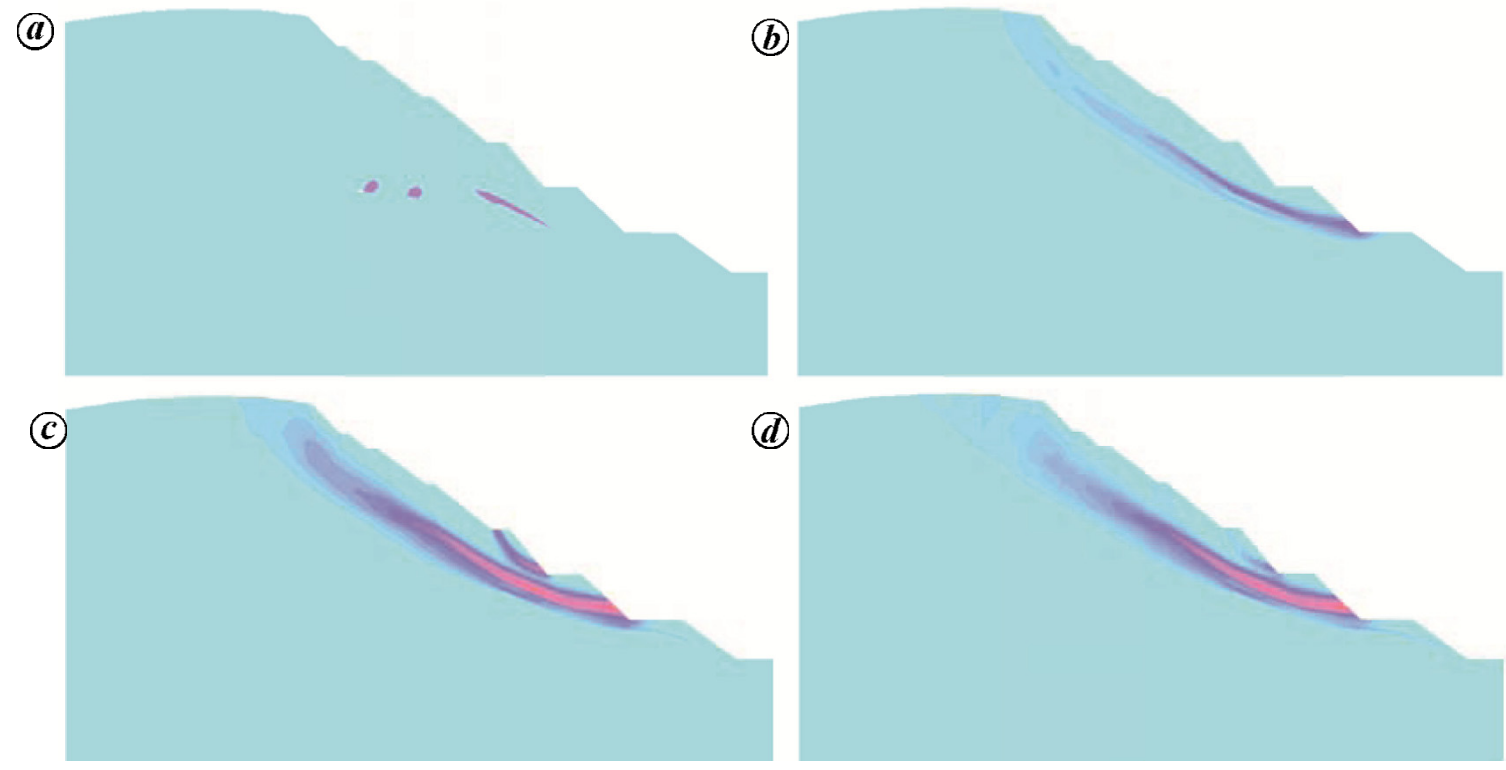

Figure 6. The maximum shear strain increment under rainfall conditions. $\boldsymbol{a}$, 1-day rainfall; $\boldsymbol{b}$, 3-day rainfall; $\boldsymbol{c}, 3$ days after rainfall; $\boldsymbol{d}, 7$ days after rainfall.

Table 3. Parameters for SWCC and $k_{w}$ function

\begin{tabular}{lcccc}
\hline Stratum & $\theta_{s}$ & $a(\mathrm{kPa})$ & $m_{v}(\mathrm{kPa})$ & $k_{\text {sat }}(\mathrm{cm} / \mathrm{s})$ \\
\hline $\mathrm{SU}$ & 0.38 & 6 & $1.0 \times 10^{-5}$ & $5.91 \times 10^{-3}$ \\
$\mathrm{Q}_{4}^{\mathrm{TL}}$ & 0.39 & 3 & $2.1 \times 10^{-4}$ & $1.13 \times 10^{-2}$ \\
$\mathrm{C}_{3} \mathrm{c}-\mathrm{P}_{1} \mathrm{~m}$ & - & - & - & $1.00 \times 10^{-5}$ \\
\hline
\end{tabular}

Noting that the bottom layer has little influence on this landslide, the parameters of the upper two layers are considered as normally distributed (Tables 1 and 2).

\section{Slope stability and reliability analysis}

\section{Numerical modelling and boundary conditions}

The numerical model of the slope consists of 4164 elements and 4311 nodes. The maximum matric suction is assumed to be $100 \mathrm{kPa}$. The ground surface of the slope is applied a constant flux as the rainfall infiltration boundary condition. Considering that the maximum infiltration capacity of soil is limited by $k_{w}$, the actual rainfall infiltration intensity is set to be a constant once $I$ is equal to or greater than the infiltration capacity of soil. The surface runoff rooted from the redundant rainwater is not taken into consideration, because the focus of this study is on the influence of infiltration.

According to the rainfall grading of China Meteorological Administration ${ }^{24}$, the rainfall intensity values of 5.0, $17.5,37.5,75.0,125.0$ and $270.0 \mathrm{~mm} / \mathrm{d}$ are used as the different rainfall inducement conditions, which stands for light rain, moderate rain, heavy rain, violent rain, rainstorm, and extraordinary rainstorm, respectively. $F_{S}$ and $P_{f}$ of the mining slope are determined during and after rainfalls for engineering safety assessment.

CURRENT SCIENCE, VOL. 116, NO. 4, 25 FEBRUARY 2019 

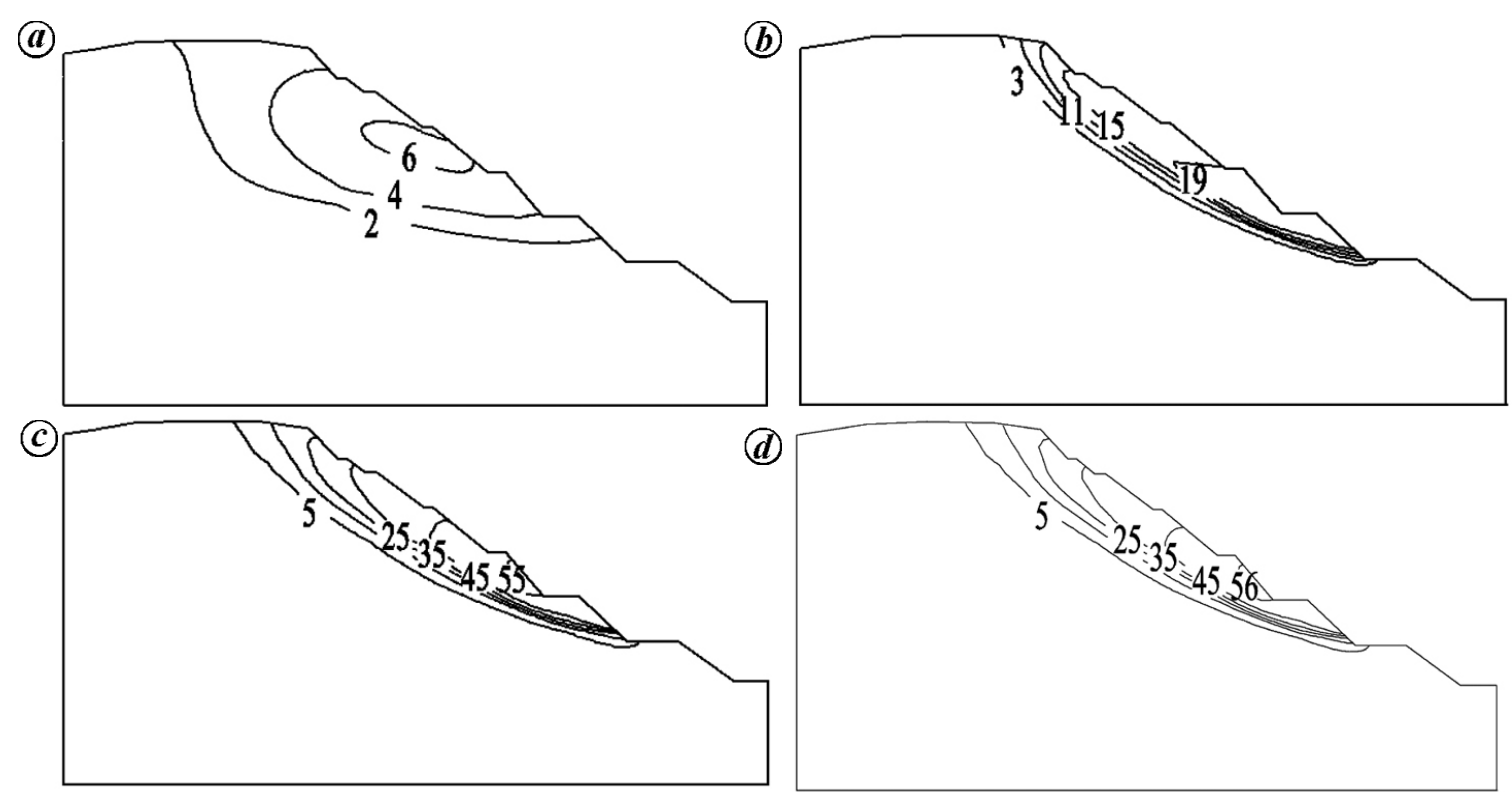

Figure 7. Displacement in several typical timesteps (unit: mm). $\boldsymbol{a}, 1$-day rainfall; $\boldsymbol{b}, 3$-day rainfall; $\boldsymbol{c}, 3$ days after rainfall; $\boldsymbol{d}, 7$ days after rainfall.
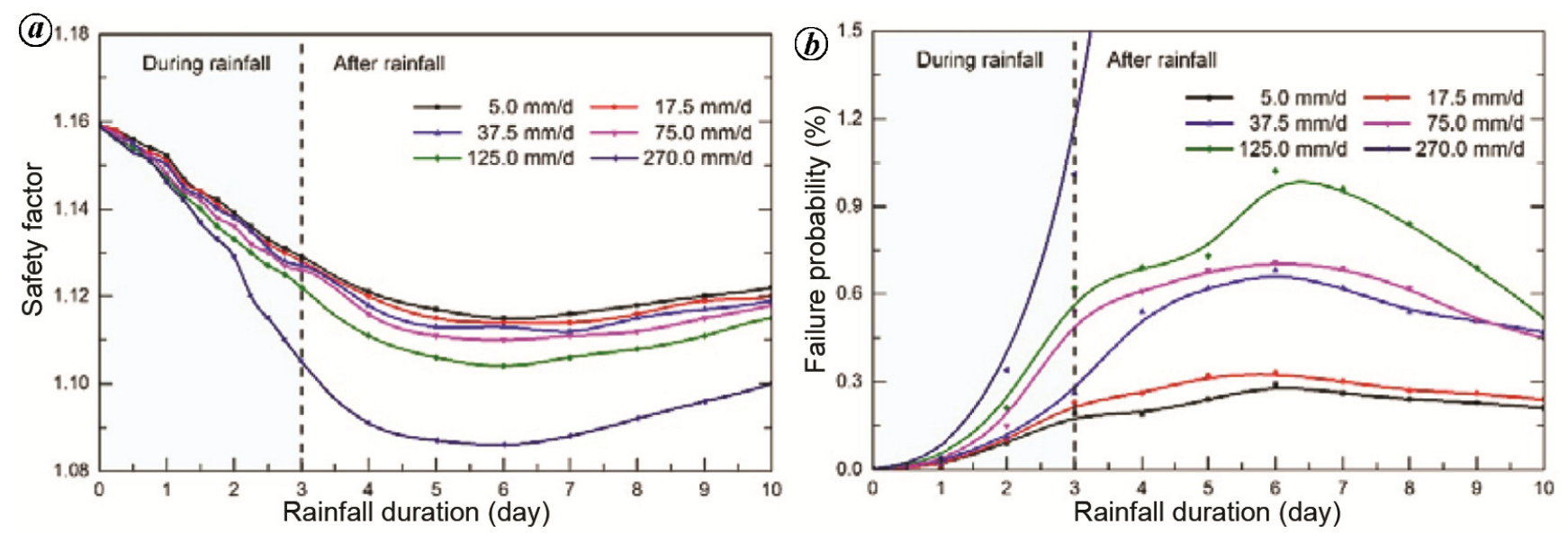

Figure 8. $\quad F_{S}(\boldsymbol{a})$ and $P_{f}(\boldsymbol{b})$ of the slope under different rainfall conditions.

\section{Analysis of results}

Pore water pressure: Figure 4 presents the changes of matric suction in the slope during and after rainfalls $(I=75 \mathrm{~mm} / \mathrm{d})$. It is seen that the value of $\psi_{w}$ in the slope is sensitive to the effective rainfall infiltration. When a continuous 3-day rainfall occurs, the negative $\psi_{w}$ in the top zone of the slope increases by approximately $20 \mathrm{kPa}$. The water table rises by more than $10 \mathrm{~m}$. The soil in the fifth and sixth steps turns into saturated state firstly. When the 3-day rainfall stops, the negative $\psi_{w}$ near the ground surface begins to decrease, but the water table has a hysteretic effect with infiltration. The water table rises to the maximum level in three days after the rainfall, which means that, to some extent, the slope would have a minimum $F_{S}$ at that time.
Safety factor and failure probability: Figure 5 a shows the variations of $F_{S}$ and $P_{f}$ of the slope for different $D$ $(I=75 \mathrm{~mm} / \mathrm{d})$. It is seen that the value of $F_{S}$ decreases continuously during and after the rainfall. $F_{S}$ reaches the minimum value in three days after rainfall. $P_{f}$ increases drastically with infiltration in the middle-late of the rainfall and after the rainfall for different $D$, even though the rising trend of $P_{f}$ slows down after the rainfall. The most dangerous $P_{f}$ occurs three days after the rainfall, which is in accordance with the variation of $\psi_{w}$, and actually implies the dangerous period of slope instability.

Figure $5 b$ presents the variations of $F_{S}$ and $P_{f}$ of the slope for different $I(D=3$ days). It shows that the value of $F_{S}$ after the rainfall decreases rapidly with the increase of $I . P_{f}$ increases drastically once $I$ is greater than $100 \mathrm{~mm} / \mathrm{d}$. According to the statistical data of the open 
pit mining slope, the acceptable $P_{f}$ of the slope is normally less than $1.0 \%$ (ref. 25). For the Yongping Copper Mine, once the intensity of 3-day rainfall is more than $100 \mathrm{~mm} / \mathrm{d}, P_{f}$ becomes unacceptable.

\section{Failure mechanism of the mining slope}

Figure 6 shows the distributions of the increment of maximum shear strain in the slope during and after rainfall $(I=75.0 \mathrm{~mm} / \mathrm{d}, D=3$ days $)$. It is seen that the maximum shear strain increment at the toe increases sharply first, then spreads to the top zone continuously. The maximum shear strain increment zone near the fifth step reaches its maximum value in three days after the rainfall. The slope above the fourth step shows large local plastic deformation and is more likely to lose stability. Therefore, the stepped slope between the third and fifth steps is more susceptible to local collapse. Figure 7 shows that the surface of the slope between the third and fifth steps has the largest deformation, while the top zone of the slope has a minor deformation $(I=75.0 \mathrm{~mm} / \mathrm{d}, D=3$ days $)$. Therefore, the distribution of the slope activity indicates that it is an advancing landslide.

\section{Discussion}

\section{Impact of I and D on the mining slope stability}

Figure $8 a$ shows the variations of $F_{S}$ of the slope during and after a 3-day rainfall. It is seen that $I$ has an obvious impact on $F_{S}$. A higher value of $I$ always leads to a more significant decrease in $F_{S}$ both during and after the rainfall. $F_{S}$ after a 3 -day rainfall indicates that water infiltration has a hysteretic effect on slope stability. For the Yongping Copper Mine, no matter what the value of $I$ is, the minimum $F_{S}$ always occurs in three to four days after a 3-day rainfall. Moreover, it is clearly seen that, for different values of $I$, the variation of $F_{S}$ follows the same trend, i.e. going up after dropping.

\section{Impact of I and D on the slope failure probability}

It is well recognized that soil properties change in space, due to soil texture, degree of density, water content, etc. Figure $8 b$ shows that the value of $P_{f}$ of the slope increases obviously with increase in $I$. The larger the value of $I$, the more remarkable the increase in $P_{f} . P_{f}$ goes up first and then decreases. It is worth noting that there is a sharp rising of $P_{f}$ on the third day, significantly exceeding $1 \%$, when $I$ equals $270 \mathrm{~mm} / \mathrm{d}$, which means that the value of $P_{f}$ is not acceptable; meanwhile, the value of $F_{S}$ is greater than 1.1 , indicating that the slope is still in stable. Therefore, it is necessary to have an overall assessment of stability by considering both $F_{S}$ and $P_{f}$. As a whole, the slope should be deemed as in the state of instability.

\section{Conclusion}

The Yongping Copper Mine slope is a large-scale rainfall-induced landslide. In this study, the hydraulic response of the slope induced by rainfall is simulated, the failure mechanism of the slope analysed, and the values of $F_{S}$ and $P_{f}$ of the slope for different rainfall conditions determined. Results indicate that rainwater infiltration will lead to increases of pore water pressure and water table during rainfall, and the infiltration has a hysteretic effect after rainfall. The deformation between elevations of $178 \mathrm{~m}$ (the third step) and $226 \mathrm{~m}$ (the fifth step) implies that the distribution of the mining slope activity is likely to be an advancing landslide. The impact of the values of $I$ and $D$ on $F_{S}$ and $P_{f}$ of the slope shows that a large value of $I$ will always cause a significant decrease of $F_{S}$ and a drastic increase of $P_{f}$ during rainfall. The variations of $F_{S}$ and $P_{f}$ imply that the most dangerous state occurs in three days after rainfall. Sometimes the value of $F_{S}$ and $P_{f}$ are not in acceptable ranges simultaneously, a comprehensive consideration should be taken by using these indices to determine the stability of the slope.

1. Dou, H., Han, T., Gong, X. and Zhang, J., Probabilistic slope stability analysis considering the variability of hydraulic conductivity under rainfall infiltration-redistribution conditions. Eng. Geol., 2014, 183, 1-13.

2. Calvello, M., D’Orsi, R. N., Piciullo, L., Paes, N., Magalhaes, M. and Lacerda, W. A., The Rio de Janeiro early warning system for rainfall-induced landslides: Analysis of performance for the years 2010-2013. Int. J. Disaster Risk Reduct., 2015, 12, 3-15.

3. Rosi, A., Peternel, T., Jemec-Auflič, M., Komac, M., Segoni, S. and Casagli, N., Rainfall thresholds for rainfall-induced landslides in Slovenia. Landslides, 2016, 13, 1571-1577.

4. Zhang, L. L., Zhang, J., Zhang, L. M. and Tang, W. H., Stability analysis of rainfall induced slope failure: A review. Proc. Inst. Civil Eng. Geotech. Eng., 2011, 164, 299-316.

5. Satyanaga, A., Rainfall-Induced Slope Failures and Preventive Measures in Singapore, Nanyang Technological University, Singapore, 2014.

6. Iverson, R. M., Landslide triggering by rain infiltration. Water Resour. Res., 2000, 36, 1897-1910.

7. Tsai, T. L. and Yang, J. C., Modeling of rainfall-triggered shallow landslide. Environ. Geol., 2006, 50, 525-534.

8. Caine, N., The rainfall intensity-duration control of shallow landslides and debris flows. Geogr. Ann. Ser. A, Phys. Geogr., 1980, 62, 23-27.

9. Guzzetti, F., Peruccacci, S., Rossi, M. and Stark, C. P., The rainfall intensity-duration control of shallow landslides and debris flows: an update. Landslides, 2008, 5, 3-17.

10. Fourie, A. B., Predicting rainfall-induced slope instability. Proc. ICE - Geotech. Eng., 1996, 119, 211-218.

11. Muntohar, A. S. and Liao, H. J., Rainfall infiltration: infinite slope model for landslides triggering by rainstorm. Nat. Hazards, 2010, 54, 967-984.

12. White, J. A. and Singham, D. I., Slope stability assessment using stochastic rainfall simulation. Proc. Comput. Sci., 2012, 9, 699-706.

13. Chen, R. H., Chen, H. P., Chen, K. S. and Zhung, H. B., Simulation of a slope failure induced by rainfall infiltration. Environ. Geol., 2009, 58, 943-952.

14. Raj, M. and Sengupta, A., Rain-triggered slope failure of the railway embankment at Malda, India. Acta Geotech., 2014, 9, 789-798. 
15. Lee, M. L., Ng, K. Y., Huang, Y. F. and Li, W. C., Rainfallinduced landslides in Hulu Kelang area, Malaysia. Nat. Hazards, 2014, 70, 353-375.

16. Tan, X., Hu, N., Li, D., Shen, M. and Hou, X., Time-variant reliability analysis of unsaturated soil slopes under rainfall. Geotech. Geol. Eng., 2013, 31, 319-327.

17. Zhu, H., Zhang, L. M., Zhang, L. L. and Zhou, C. B., Twodimensional probabilistic infiltration analysis with a spatially varying permeability function. Comput. Geotech., 2013, 48, 249259

18. Huang, F., Wang, G. S. and Tsai, Y., Rainfall reliability evaluation for stability of municipal solid waste landfills on slope. Math. Probl. Eng., 2013, 2013, 1848-1856.

19. Sinosteel Maanshan Institute of Mining Research, Geotechnical Investigation Report for the Yongping Hujiashan Slope, Maanshan, Anhui, 2007.

20. Fredlund, D. G. and Rahardjo, H., The role of unsaturated soil behaviour in geotechnical engineering practice. In 11th Southeast Asian Geotechnical Conference, 1993.

21. Vanapalli, S. K., Fredlund, D. G., Pufahl, D. E. and Clifton, A W., Model for the prediction of shear strength with respect to soil suction. Can. Geotech. J., 1996, 33, 379-392.

22. Richards, L. A., Capillary conduction of liquids through porous mediums. Physics (College. Park. Md)., 1931, 1, 318-333.
23. van Genuchten, M. T., A closed-form equation for predicting the hydraulic conductivity of unsaturated soils. Soil Sci. Soc. Am. J., 1980, 44, 892-898.

24. China Meteorological Administration, Rainfall level; http://www.cma.gov.cn/2011xzt/2013zhuant/20130620_3/2013062 002/201308/t20130816 223400.html, 2013.

25. Zhu, Y., Reliability Analysis of Slope (in Chinese), Metallurgical Industry Press of China, Beijing, China, 1993.

ACKNOWLEDGEMENTS. Thanks are due to Prof. Wei-Chau Xie (University of Waterloo, Canada) for guidance. The work is supported by the National Key Research and Development Plan of China (2017YFC1501100), Natural Science Foundation of China (11772118) and Natural Science Foundation of Jiangsu Province (BK20171006).

Received 26 April 2017; revised accepted 2 November 2018

doi: $10.18520 / \mathrm{cs} / \mathrm{v} 116 / \mathrm{i} 4 / 536-543$ 